\title{
Dynamics of the level of BIM application in Russia in 2017-2019
}

\author{
Tatyana Kisel ${ }^{1, *}$ \\ ${ }^{1}$ Management and Innovations, Moscow State University of Civil Engineering, Moscow, Russia
}

\begin{abstract}
Nowadays digitalization became one of the most significant trends of the economy and society development. Digitalization of the production and non-productive processes in various sectors of the economy allows to increase the labour productivity considerably, to provide new product quality as well as to achieve high rates of cost efficiency. Digitalization in construction is provided due to the transition to building information modeling (BIM). Implementation of BIM goes unevenly in the different countries. This paper represents the results of the research of dynamics of the level of BIM implementation in Russia during 2017-2019. The research, carried out in 2017 and 2019 included 2 blocks. The first of them is the telephone poll, which acted as the quantitative research. It allowed to extend the result for all the population owing to the volume and quality of the selection. The second block is the online questioning. Despite of rather huge number of the received questionnaires, this research is actually qualitative and it allows to establish the reasons of introduction or refusal of BIM, its main benefits, etc. The results of the research proved that the quantity of the organizations using BIM did not changed during d 2017-2019 and remained at the level of $22 \%$. This result is interesting as the transfer from the accomplishment of the state order to accomplishment with obligatory application of building information modeling is indented in Russia. the explanation of the lack of the increase in the quantity of organizations using BIM. BIM introduction demands the considerable costs connected with the acquisition of equipment and software, retraining of personnel and often the organization restructuring. There results of the online questioning confirm that. During 201702019 the financial resources availability increased its influence considerably as the condition of BIM technologies implementation (among the organizations which are not using BIM). The improvement of works quality, the increase in the production efficiency (including reduction in cost and terms of works, the increase in economic return and profitability), search of ways of improving competitiveness, the requirement of the customer are the main reasons of BIM introduction (in decreasing order of the importance). The improved understanding of the project by all the participants, high quality of the project; availability of information, fast data transmission and exchange of information are noted as benefits of BIM application. It is noted, that most of respondents received the result, which exceeded their expectations thanks to BIM introduction: the excess of the result over expectations was observed by $77 \%$ of respondents in 2017 and by $80 \%$ of respondents in 2019.
\end{abstract}

\section{Introduction}

Digitalization becomes one of the most significant trends of the economy and society development. In fact, digitalization means the tendency to transfer, processing and storage of information in the electronic form. These processes are promoted by several factors:

1) growth of quantity of personal computers. According to the statistical data, the total quantity of households with personal computers grew from $27,3 \%$ to $49,7 \%$ from 2005 to 2019 [1];

2) the growth of quantity of smartphones users worldwide. So, 2019 there is more than 3 billion of them in 2019 (more precisely than 3,2 billion) [3];

3 ) the growth of the quantity of Internet users. In $2020,62 \%$ of the total world population use Internet (in Europe and North America $90 \%$ of the population use Internet) [4].
At the same time the level of digitalization of business grows too [4]. It is caused by the complication of production and auxiliary processes at the enterprises. It causes the necessity of processing of great amount of mutually connected data, ensuring the regulated access to them for various participants of the production process. That leads to the growth of the specialized software volume.

The use of modern digital technologies allows to increase the speed of data transmission and also provides the possibility of big data arrays processing. We can also speak of cutting of the expenses for search, replication, tracking validation of data and documents as well as their transportation and transfer $[5,6]$.

Construction is one of the economy branches, involved in digitalization. Construction projects of today are difficult, information saturated. It is important that the comfort and safety of many people depends on the

\footnotetext{
*Corresponding author: SilantievaTN@mgsu.ru
} 
quality of decisions in construction (quality of the project, its implementation, the subsequent operation). Therefore, the construction industry has to stand in vanguard of digitalization. Building information modeling (BIM) is the basis of digitalization in construction [7]. The benefits of BIM application are already described in many sources $[8,9 ; 10,11,12,13]$ and they also get confirmation by the means of specific examples $[14,15,16]$.

Such countries as Great Britain, the USA, Singapore, France and the Scandinavian countries are at the forefront of BIM application. So, in Great Britain BIM is to be applied for all the state projects since 2016, and in Singapore it is necessary since 2015. The conditions of BIM application for the state projects are also implemented in the USA in some states [17]. Specialists in UAE, China, Germany, Australia work with BIM actively [18].

In Russia the research of practice of BIM application has been also conducted on regular basis since 2016 . The research, devoted to the measurement of the level of BIM application in the Russian construction organizations were carried out twice under the author's supervision and with the organizational support of the Russian consulting company Konkurator [19]. The first research was carried out in 2017. It became the first research of that type. And the second research had been completed by the end of 2019 .

The data, gained within the research allowed to estimate the dynamics of processes of BIM introduction in Russia for the first time. This article is devoted to the analysis of dynamics of the level of BIM application in Russia during 2017-2019.

\section{Materials and Methods}

The research is based on the application of the social research methods. So, some data of the quantitative research were obtained by the method of telephone poll.

Within the telephone poll the selection size allowing to speak about the low probability of a mistake was provided. Respectively, high quality of the received results is provided. That proves the opportunity to extend the results of the research to the whole Russian construction industry with a definite statistical error. Representatives of 427 organizations participated in the poll in 2017 and 541 representatives participated in it in 2019. Contact information of the enterprises for the telephone poll was taken from the open sources, selection of the enterprises was performed spontaneously.

The enterprises of the investment-and-construction sphere of various functional orientation acted as the target audience (including developers, technical customers, general contractors, designers and architects, construction enterprises, etc.).

A short questionnaire was used as the tool of the poll. The results of the telephone poll allow to make some conclusions about the quantity characteristics of population, e.i. how many organizations of the investment-and-construction sphere introduced and began to use technologies of information modeling in their work. At the same time the extent of introduction was not estimated.

The online questioning method was also used for deeper analysis of the processes of BIM introduction. The purposes include the identification of the main obstacles to the development of technologies of information modeling, compliance of expectations from $\mathrm{BIM}$ introduction to the received results as well as the plans for introduction or the reasons for refusal of BIM introduction. 190 completed questionnaires were received within the research in 2017 and 174 questionnaires were received in 2019.

The online questionnaire acted as the tool of the survey. The enterprises and the organizations of the investment-and-construction sphere of various functional orientation got into the selection structure. The selection was created spontaneously on the basis of the initiative proceeding directly from the respondents. It does not allow to extend the results of online questioning to all the population, however it allows to make the analysis of causes-and-effect relationships, as that is characteristic of the qualitative research.

The results provided in this article are based on the application of such general scientific method as comparison. This method allows to estimate the dynamics of indicators of BIM application in Russia during 2017-2019.

\section{Results}

\subsection{Results of the telephone poll}

The main question was "Does your organization use BIM technologies in the Activity?".

The research carried out in 2017 proved that $22 \%$ of the 427 respondents apply technologies of information modeling in their activity.

In 2019 the research proved the lack of dynamics of the indicator. Representatives of 541 organizations were interviewed. However, the result remained invariable $22 \%$ (fig. 1 ).

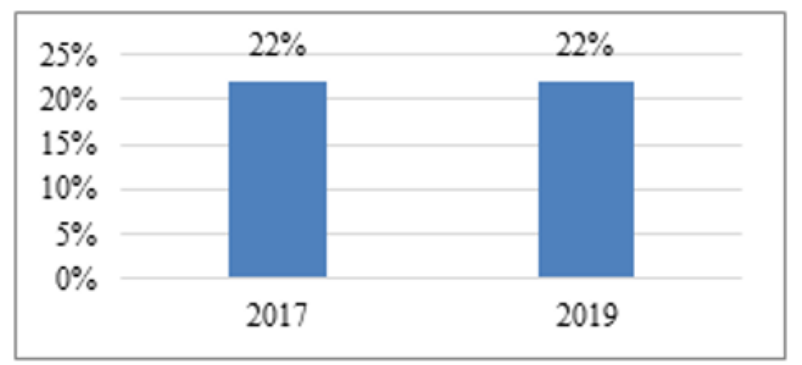

Fig. 1.The quantity of the organizations which have answered the question "Whether Your Organization in the Work Applies BIM Technologies?" positively.

The lack of real increase in the quantity of the organizations using BIM demands the search of the reasons of braking in distribution of technologies. The integrated analysis of the general trend of the industry development allows to find the possible reasons of 
current situation. So, the official statistics data shows the decrease in the investments into fixed capital of the construction organizations, since 2016 both in absolute measures, and percentage of the total amount of investments. The decrease in the investments into fixed capital proves the decrease in the investments into the new equipment and technologies. In this situation it is rather difficult to speak about the implementation of BIM technologies, as it demands the considerable capital investments connected with the acquisition of specialized software and equipment.

The quantity of those, who found it difficult to answer the question, is interesting for the comparison. There were $22 \%$ of them in 2017. Among them there were also some respondents, incompetent to give the exact answer, as well as those who just did not know what is BIM. In 2019 only $16 \%$ of the respondent found it difficult to answer, at the same time only 8 respondents $(1.5 \%)$ were recognized that they do not know what is BIM.

That means that, despite of the lack of the growth of the general share of the enterprises using BIM, the share of the respondents, having the idea of what is the essence of the information modeling technologies, has considerably grown. Such trend is not surprising, the information background devoted to BIM technologies became saturated, round tables and academic and research conferences, etc. are held. It corresponds to the growth of the level of digital economy in Russia reflected in the international ratings [20].

The respondents who negatively answered the question about the BIM application, were asked the additional question, whether they have any plans of introduction of BIM in the short term. Let us note that the quantity of the organizations planning BIM introduction had considerably reduced by 2019 (fig. 2).

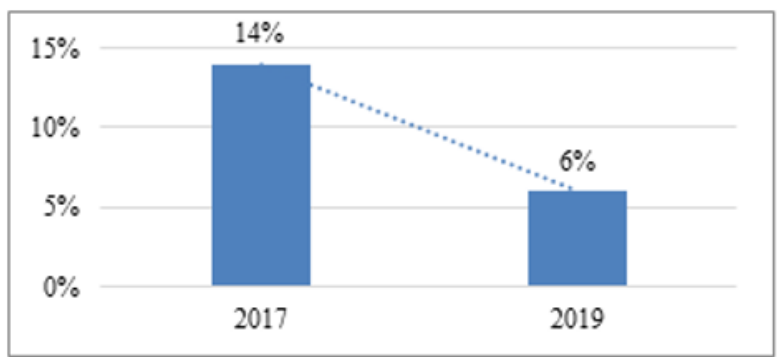

Fig. 2.Have plans for BIM introduction (among the quantity of respondents, not applying BIM).

The general economic situation has probably led to such a trend.

\subsection{Results of online questioning}

Questions of this block assume the differentiation for 2 groups of respondents:

- the respondents who answered the question about the use of technologies of information modeling positively, answered the questions about their experience of BIM application, received results, reasons of introduction and the main obstacles to introduction of BIM;

- the respondents who answered the question about the use of technologies of information modeling negatively, answered the questions of reasons for refusal of BIM, availability of plans for BIM introduction.

As it has been noted earlier, the selection was created from some quantity of representatives of the organizations who have wished to participate in the research. Most of the participants were the organizations performing project works (more than 50\% both in 2017 and in 2019). Architectural bureaus, general contractors, contractors, developers, operating and the prospecting organizations and other organizations of the investmentand-construction sphere also became the respondents.

The distribution of the respondents on the matter of the use of BIM was the following (fig. 3):

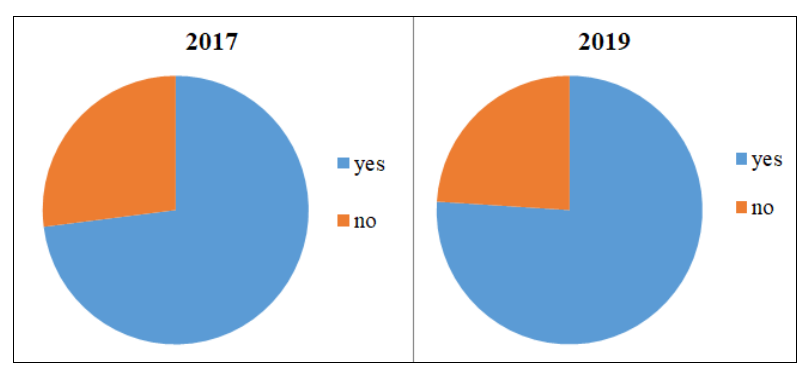

Fig. 3.Distribution of answers of the questionnaire for the question: "Do you use BIM working on projects in your organization?".

There are organizations with various work experience among the BIM users (fig. 4):

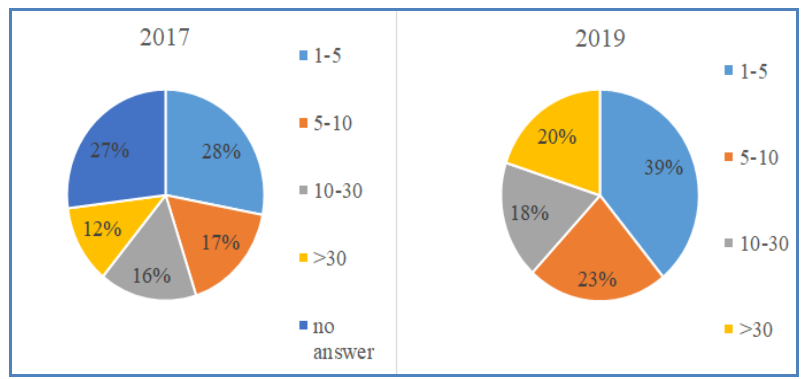

Fig. 4. The quantity of the projects implemented with the use of BIM.

As we can see, there is a shift towards the organizations with small work experience with BIM both in 2017 and in 2019.

It is interesting that significant changes in determination of the reasons of implementation of technologies of information modeling are observed (in the group of companies, using BIM). In 2017 almost identical number of respondents called the increase in production efficiency, improvement of quality of works and search of ways of improving competitiveness as the reasons of BIM introduction $(50 \%, 49 \%$ and $46 \%$ respectively). The requirement of customers was noted at the level of $22 \%$. The improvement of works quality and production efficiency had increased the importance by $2019,71 \%$ and $69 \%$ of respondents respectively are 
noted. Other reasons remained at the same level on average (figure 5):

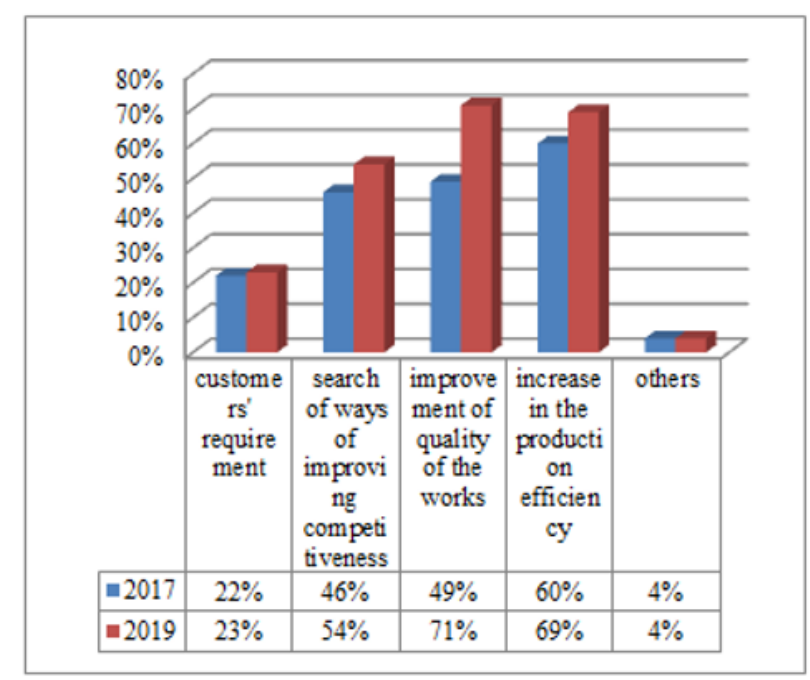

Fig. 5.Distribution of answers for the question about the reasons of the implementation of BIM technologies in the organization.

The question aimed on the identification of the main advantages which the use of BIM gives (the question became one of key questions of the researches). What are the advantages which the use of BIM gives to your organization?) The main benefits of BIM application did not change during 2017-2019. Only some fluctuations of indicators are observed. The improved understanding of the project by all the participants, high quality of the project, its availability and fast information transfer are still in the lead (fig. 6):

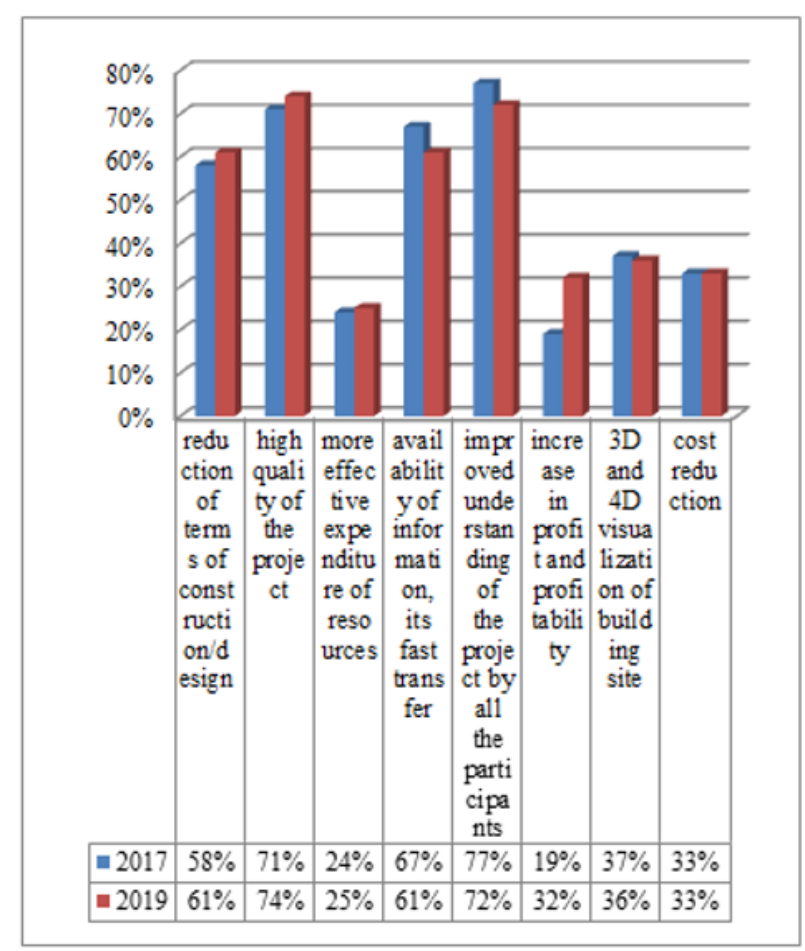

Fig. 6.Main benefits of BIM application.
Except the main possible answers, the respondents noted the following benefits:

- satisfaction of the customer;

- the use as the instrument of sales;

- collective work establishing;

- the decrease in mistakes and improvement of the end product quality.

Answering this question, the respondents, as a rule, noted several benefits at once. That speaks about high performance of BIM application and various manifestations of the gained effect.

The comparison of the expectations from the implementation of BIM technologies and the received result became one more important question of the questionnaire. It is, perhaps, the major aspect characterizing the results of BIM introduction and the efficiency of its application (though not in concrete and exact figures). The respondents were offered to estimate their expectations from BIM introduction and the real gained effect according to the scale from 1 to 10 , where 1 means that the real effect completely does not meet expectations and has not justified them, 5 means that the gained effect completely correspond to those expectations which were assigned to BIM introduction, 10 means that the effect received repeatedly exceeds the initial expectations. The distribution of answers is presented in fig. 7 :

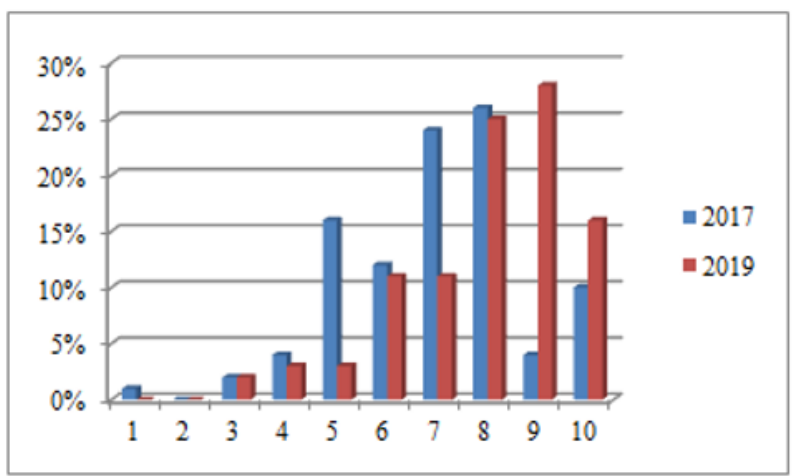

Fig. 7.Satisfaction with the results of BIM introduction.

The results of the comparisons of the expectations from implementation of BIM technologies and the received result changed slightly. In general, the satisfaction with results of use of BIM has positive trend: in 2017 excess of result over expectations was observed at $77 \%$ of respondents, in 2019 - at $80 \%$.

The link between the use of BIM experience and the satisfaction with the results of its introduction was revealed during the analysis. As a rule, the low satisfaction is characteristic of the organizations, having small work experience.

Dynamics of distribution of answers on the reasons interfering the distribution of BIM in Russia is also interesting.

The influence of such factors as the deficiency of qualified personnel (this indicator increased from $61 \%$ in 2017 to $73 \%$ in 2019) and high implementation cost (this indicator increased from $40 \%$ in 2017 to $52 \%$ in 2019) 
increased in group of the organizations using BIM (fig. 8):

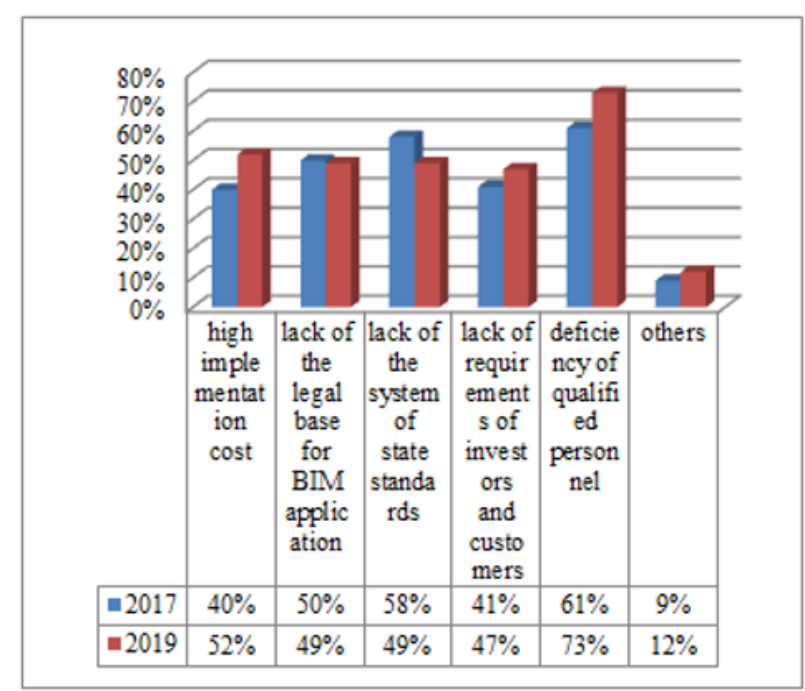

Fig. 8.Main reasons interfering the distribution of technologies of information modeling in Russia (according to the organizations using BIM).

The organizations which are not using BIM, the main obstacles consider the high implementation cost (the indicator increased from $43 \%$ in 2017 to $57 \%$ in 2019) and the deficiency of qualified personnel (fig. 9):

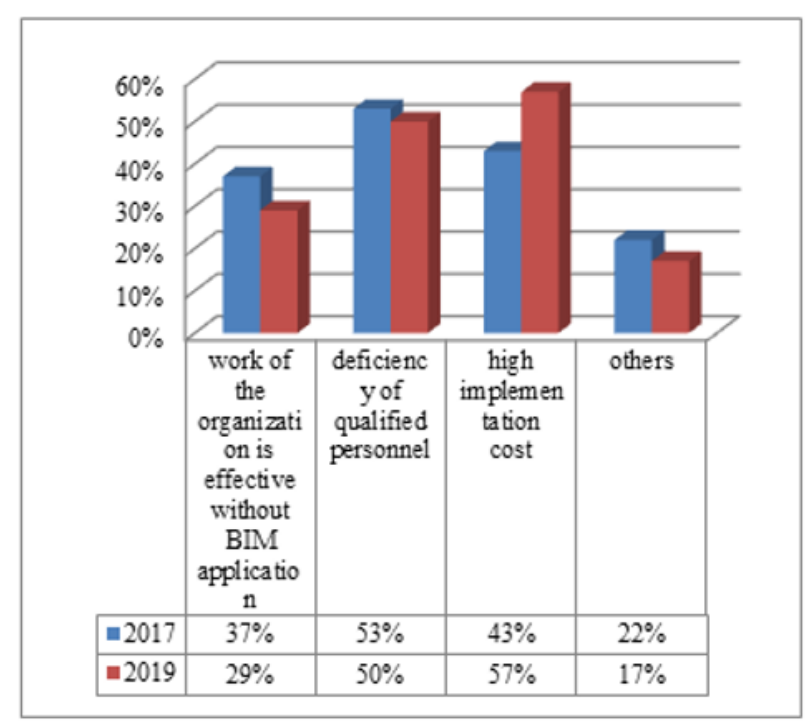

Fig. 9.Basic reasons of refusal of BIM introduction.

The availability of financial resources as the condition of implementation of BIM technologies (for the organizations which are not using BIM) has considerably increased its influence for 2 years. So, i $43 \%$ of respondents noted it in $201757 \%$ noted it in 2019. Thus, the financial matters began to have the increasing importance in 2019.

$60 \%$ of the respondents (among the organizations which are not using BIM) planed the transition to BIM within the next 5 years in 2019. In 2017 the introduction of BIM was planned only by $32 \%$ of the respondents (fig. 10):

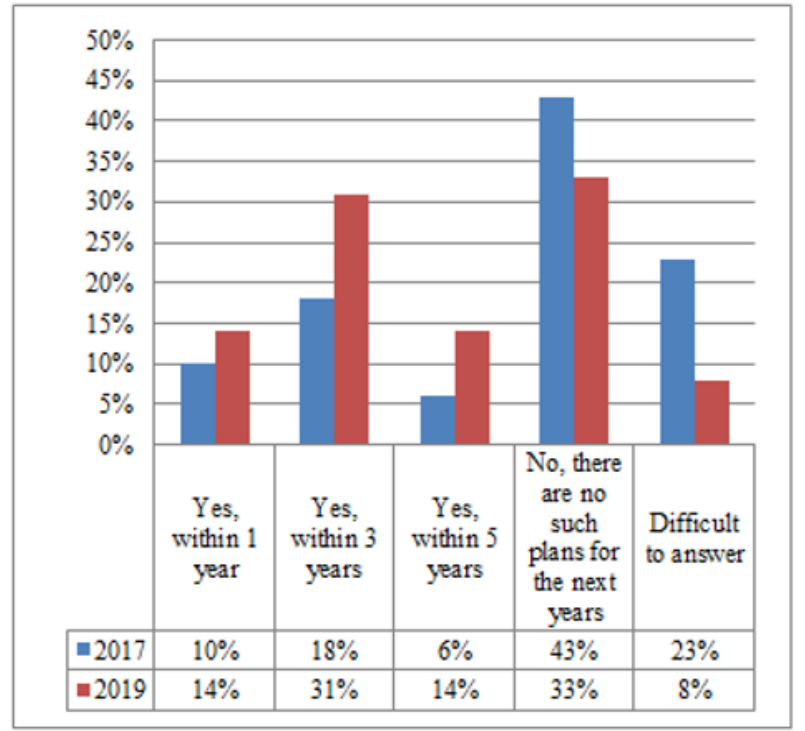

Fig. 10.Plans of the respondent organizations for the BIM introduction for the next 5 years.

Such dynamics proves that the implementation of technologies of information modeling by increasing the quantity of the organizations is perceived as the conscious need for ensuring development on the strategic prospect. It should be noted that in this case the results of the telephone poll contradict the results of the online questioning. According to the telephone poll the quantity of the organizations (not using BIM), planning its introduction decreased considerably while according to the results of the online questioning it increased. In this case it is necessary to explain such difference with the features of selection during the online questioning. The questioning had an initiative character. That means, the interested participants took part in it. Perhaps, there were more of those who plan BIM introduction among them, therefore they were interested in the subject.

The question, what internal or external motives can lead the organization to BIM introduction was also asked to the group of the respondents who do not use BIM technology at the moment of carrying out the research. The financial factor also came to the forefront in 2019 and became the most significant factor. For comparison in 2017 it was noted by only $6 \%$ of the respondents.

\section{Conclusion}

Determination of the level of use of BIM technologies by the Russian companies, i.e. the average share of the enterprises of the investment-and-construction sphere, using BIM technologies and BIM tools regardless of the depth and experience of the use, became the main objective of the research.

The results of the telephone poll in 2019 proved that the level of BIM application did not change comparing with that in 2017 and its value is $22 \%$. That allows to speak about the decrease in the investments into fixed capital in construction in Russia during the last 4-5 years as well as abut the decrease in the amounts of works 
which are being carried out in the form of "Construction" activity (in the comparable prices).

The author also analysed the results of the online questioning which purpose was to study the opinion of target audience about the main benefits of BIM and the main obstacles to it in Russia of today.

The question about the reasons which have pushed the organization to implementation of BIM technologies became one of key questions of the research for the organizations, using BIM. The improvement of quality of works, the increase in the production efficiency (including reduction in cost and terms of works, the increase in economic return and profitability), search of ways of improving competitiveness and also the requirement of the customer became such reasons.

The respondents were also offered to estimate the expectations from BIM introduction and the real gained effect. Most of respondents noted, that the effect of introduction of BIM which was really gained exceeded the expectations.

The deficiency of qualified personnel and high implementation cost became the main obstacles to BIM introduction. And the financial questions got in 2019 the great importance in comparison with the results of 2017. All this promotes the public awareness of technologies of information modeling in Russia.

\section{References}

[1] Thomas Alsop, Computer penetration rate among households worldwide 2005-2019 [Electronic resource] Available at: https://www.statista.com/statistics/748551/worldwid e-households-with-computer/

[2] S. O'Dea, Smartphone users worldwide 2016-2021 [Electronic resource] Available at: https://www.statista.com/statistics/330695/numberof-smartphone-users-worldwide

[3] Internet usage statistics, The Internet Big PictureWorld Internet Users and 2020 Population Stats [Electronic resource] Available at: https://www.internetworldstats.com/stats.htm

[4] G.I. Abdrakhmanova, G.G. Kovalyova, Digitalization of business in Russia and abroad [Electronic resource] Available at: https://issek.hse.ru/news/309213798.html

[5] Avi Goldfarb, Catherine Tucker, Digital economics (Toronto, Cambridge, 2017) 89

[6] Rumana Bukht, Richard Heeks, Defining, Conceptualising and Measuring the Digital Economy 13, 2 (2018)

[7] O. Wyman, Digitalization of the construction industry: the revolution is underway [Electronic resource] Available at: https://www.oliverwyman.com/content/dam/oliverwyman/v2/publications/2018/july/OliverWyman_Di gitalization_in_the_construction_industry_web_fina 1.PDF
[8] Salman Azhar, Building Information Modeling (BIM): Trends, Benefits, Risks, and Challenges for the AEC Industry, Leadership and Management in Engineering 11, 3 (July 2011) [Electronic resource] Available at https://ascelibrary.org/doi/10.1061/\%28ASCE\%29L M.1943-5630.0000127

[9] Nancy Reyes, Top 5 Benefits of BIM Construction [Electronic resource] Available at: ttps://hmcarchitects.com/news/top-5-benefits-ofbim-construction-2020-05-13/

[10] Juan Rodriguez, Building Information Modeling (BIM) Benefits Per Profession [Electronic resource] Available at: https://www.thebalancesmb.com/buildinginformation-modeling-bim-benefits-845045

[11]Jian Li, Ying Wang, Xiangyu Wang, HanbinLuo, Shih-Chung Jessy Kang, Jun Wang, Jun Guo, Yi Jiao, Benefits of Building Information Modelling in the Project Lifecycle: Construction Projects in Asia [Electronic resource] Available at: https://www.researchgate.net/publication/27455844 5_Benefits_of_Building_Information_Modelling_in _the_Project_Lifecycle_Construction_Projects_in_ Asia. DOI: $10.5772 / 58447 /$

[12] P.M. Diaz, Analysis of Benefits, Advantages and Challenges of Building Information Modelling in Construction Industry, Journal of Advances in Civil Engineering 2, 2, 1-11 (2016) [Electronic resource] Available at: /https://www.researchgate.net/publication/30562282 1_Analysis_of_Benefits_Advantages_and_Challeng es_of_Building_Information_Modelling_in_Constru ction_Industry

[13] Peter Mesároš, TomášMandičák, Exploitation and Benefits of BIM in Construction Project Management, IOP Conf. Series: Materials Science and Engineering 245, 062056 (2017) [Electronic resource] Available at: https://iopscience.iop.org/article/10.1088/1757899X/245/6/062056/pdf. DOI: $10.1088 / 1757-$ 899X/245/6/062056

[14]R. Trieu, Seven Examples of Buildings Around the World Using BIM to Meet LEED, Architecture (28 June 2019) [Electronic resource] Available at: https://redshift.autodesk.com/bim-examples/

[15]V. Delaqua, 10 Projects in Which BIM was Essential [Electronic resource] Available at: https://www.archdaily.com/920839/10-projects-inwhich-bim-was-essential

[16] Kainuu Hospital - The Best Example of Deep BIM Collaboration [Electronic resource] Available at: https://www.tekla.com/resources/casestudies/kainuu-hospital-the-best-example-of-deepbim-collaboration

[17] PropTech in Russia: The overview of the practice of the use of BIM technologies and the innovative solutions in the field of design [Electronic resource] 
Available at: https://www.pwc.ru/ru/assets/proptech-2020.pdf

[18] Leading Countries with BIM adoption [Electronic resource] Available at: https://www.unitedbim.com/leading-countries-with-bim-adoption/

[19]Digital transofrmation in construction. BIM technologies [Electronic resource] Available at: http://concurator.ru/

[20] G.I. Abdrakhmanova, K.O. Vishnevsky, L.M. Gokhberg, et al. Indicators of digital economy: 2019: statistical collection (Moscow, Higher School of Economics National Research University, 2019) 248 